
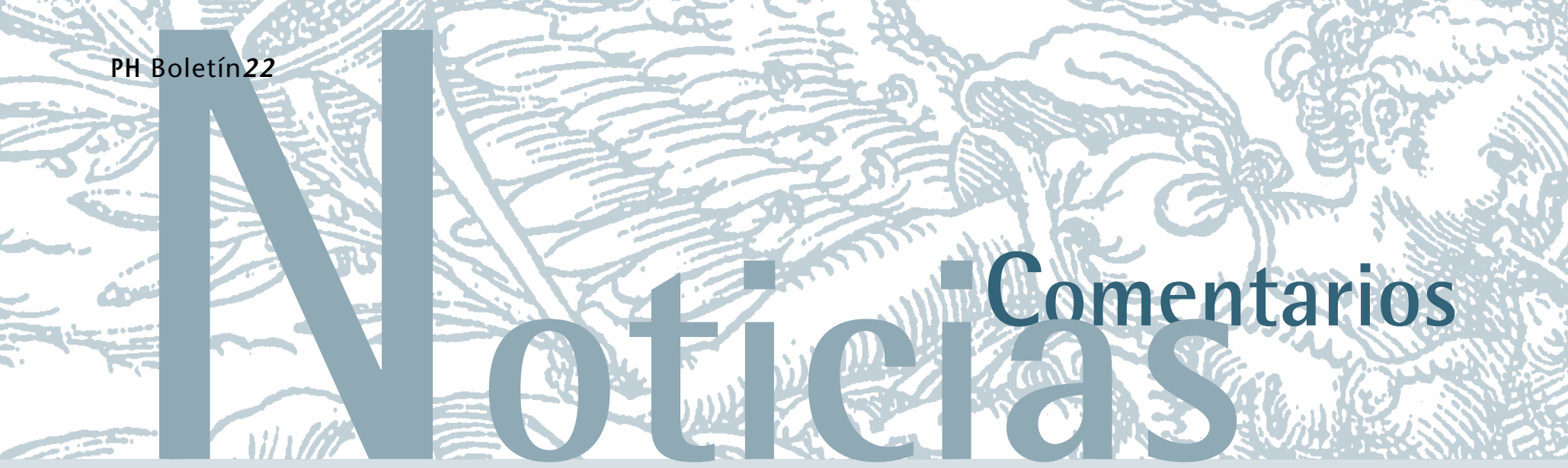

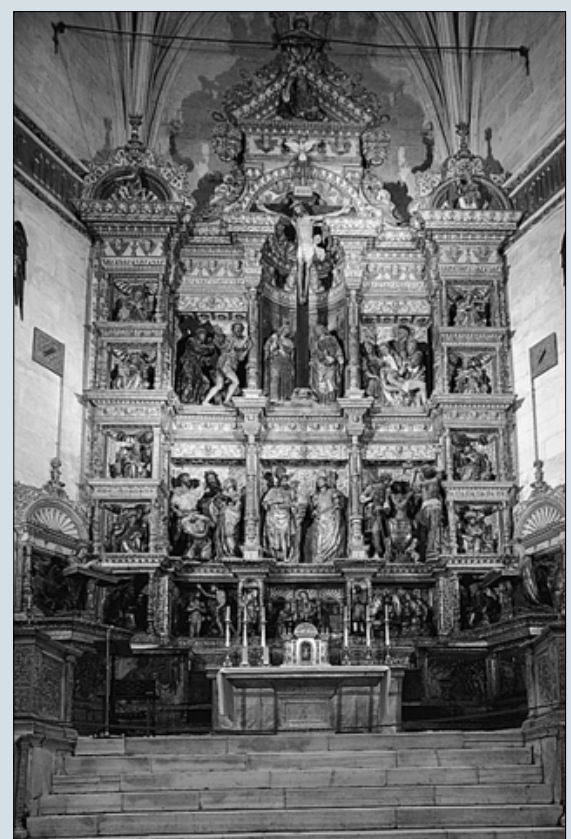

\section{INTERVENCIÓN DEL INSTITUTO ANDALUZ DEL PATRIMONIO HISTÓRICO EN EL RETABLO MAYOR DE LA CAPILLA REAL DE GRANADA}

\section{EI I.A.P.H. y la Capilla Real de Granada: proyectos y actuaciones}

La Capilla Real de Granada es un destacado ejemplo del patrimonio histórico de Andalucía. La calidad y abundancia de las obras de arte que conserva, la monumentalidad de su arquitectura, la belleza de sus espacios y, sobre todo, los valores simbólicos del conjunto, la convierten en un referente emblemático de nuestra historia y nuestra cultura.

A finales de los años ochenta se manifestaron de forma preocupante ciertos problemas de conservación en parte de la colección y en determinados los espacios de la capilla (Museo). La importancia patrimonial del recinto aconsejaba abordar la situación con rigor, desde una perspectiva científica y técnica de alto nivel.
Para atender estos requerimientos, el Instituto Andaluz del Patrimonio Histórico elaboró en 1990 un proyecto de intervención, de sólido contenido metodológico que, en una primera fase, daba respuesta a los problemas más importantes que presentaban la colección y el museo. En la empresa, el I.A.P.H. contó con la colaboración de prestigiosas instituciones internacionales especializadas en conservación del patrimonio histórico, (Instituto Real de Bruselas y el I.C.R. de Roma) y en investigación (Universidades Libre de Bruselas y Granada). Los postulados teóricos del proyecto fueron debatidos en un curso internacional celebrado en setiembre de 1991, publicándose las conclusiones en la obra "Un proyecto para la Capilla Real de Granada", editada por el propio Instituto a finales de ese año.

Entre 1990 y 1992 se abordó la conservación de la estructura lignaria del retablo de la Pasión de Jacobo Florentino y de las pinturas que contiene, exceptuando el tríptico de Dierick Bouts. Se realizó el tratamiento de conservación de toda la colección pictórica sobre tabla del Museo.

En este período también se definió el programa museológico y museográfico de las colecciones, que incluyeron importantes contenidos en materia de conservación preventiva. Este trabajo se materializó en la nueva instalación del museo inaugurada en 1992.

Por último, entre 1994 y 1995 se realizó la intervención integral en la casulla del terno blanco chapado del Rey Fernando el Católico (véase número 14, marzo 1996, de esta revista).

De forma paralela, se acometió una labor de investigación documental de las colecciones expuestas en el museo y del resto de bienes muebles conservados en la Capilla Real, incluido el retablo mayor. Las citadas colecciones también fueron objeto de una completa labor de investigación científica.

En esta fase quedó fuera de las actuaciones la intervención en el Retablo Mayor.

\section{Continuación del proyecto: convenio de colaboración.}

Para dar continuidad a este importante proyecto, la Consejería de Cultura de la Junta de Andalucía, la Fundación Caja de Madrid y el Arzobispado de Granada han firmado un convenio de colaboración que va a permitir la restauración del Retablo Mayor y la cabecera de la Capilla Real.

Según especificaciones del Convenio, corresponde al Instituto Andaluz del Patrimonio Histórico la formulación del proyecto de intervención y su dirección, incluyendo investigaciones analíticas, estudios históricos, levantamiento planimétrico y fotografías normales y técnicas. El I.A.P.H. instalará el taller necesario para el tratamiento de las esculturas e intervendrá en la arquitectura lignaria del retablo, según proceda y se derive de los estudios previos necesarios.

Corresponde a la Fundación Caja de Madrid la financiación de la ejecución material del proyecto antes descrito y los gastos de comunicación y difusión.

Por último, el Cabildo de la Capilla Real acometerá la intervención en el entorno del retablo (cabecera) según proyecto específico que se redactará a tal efecto, dispondrá los medios auxiliares necesarios para la realización de las investigaciones y ejecución del proyecto y contratará el equipo profesional necesario.

El plazo de duración de las actuaciones previstas en el Convenio, que fue suscrito el pasado 3 de noviembre, es de dos años y la inversión total asciende a 83 millones de pesetas.

\section{El retablo mayor y su valoración patrimonial}

El retablo mayor de la Capilla Real es obra de excepcional valor en el contexto del patrimonio histórico andaluz, no sólo por lo que significa en la introducción de las formas renacentistas en territorio andaluz sino por 


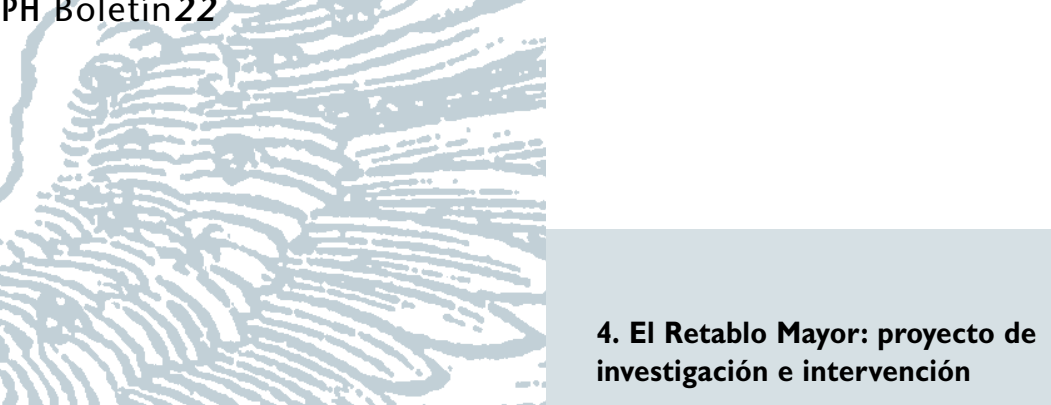

minn

ral, como documento plástico bien expresivo, a través de su complejo programa iconográfico, de la unidad religiosa, política y territorial impuesta por los Reyes Católicos.

Concebido para el primer templo cristiano levantado tras la conquista del último enclave islámico en España, el retablo se articula siguiendo esquemas renacentistas, a modo de arco triunfal romano con sotabanco, banco, dos cuerpos con cinco calles y ático de remate, todo ello ornamentado con motivos decorativos extraídos del léxico clasicista típico del primer renacimiento español.

La historiografía tradicional ha considerado a Felipe de Bigarny o de Borgoña como el autor del retablo, siguiendo el testimonio expresado por Bermúdez de Pedraza en su Antigüedad y Excelencias de Granada (1608), y fechándolo entre 1520 y 1522.

Recientemente, documentación descubierta en la sección de Contaduría Mayor del Archivo General de Simancas por el profesor Jesús Suberbiola ha permitido confirmar la atribución tradicional. Así, hoy sabemos que Felipe de Bigarny recibió en 1519 una cantidad a cuenta por el retablo que estaba realizando para la Capilla Real de Granada y que había contratado el 17 de Mayo de ese año, por un importe total de $\mathbf{1 . 5 0 0 . 0 0 0}$ de maravedíes.

No obstante, la importancia de esta documentación que arroja nuevos datos en relación con la historia de la ejecución del retablo, es necesario considerar la realización de una obra de esta envergadura como una labor de equipo según fórmulas habituales para este tipo de empresas. Así, junto al maestro borgoñón contratante del retablo, la crítica especializada ha señalado la posible intervención en la obra de Alonso Berruguete, activo en Granada por esas fechas y cuyo influjo parece evidente en la decoración escultórica del conjunto, del italiano Jacobo Florentino, a quien quizás pueda deberse el diseño de la estructura arquitectónica y motivos decorativos del retablo, así como la supervisión de las tareas de talla y ensamblaje, o de los pintores Antón de Plasencia y Alonso de Salamanca, probables autores del dorado y estofado de todo el conjunto y habituales colaboradores del italiano.

\section{El Retablo Mayor: proyecto de}

El proyecto, cuya redacción aborda el Instituto Andaluz del Patrimonio Histórico, contempla, según convenio, la investigación y posterior intervención en la arquitectura lignaria y la imaginería del retablo, así como el material lapídeo de los paramentos, epigrafía y heráldica. Se estructura en las siguientes fases: l. Investigación: Estudios preliminares.

II. Diagnóstico: Estado de conservación, de- terminación de factores de alteración y patologías

III. Metodología y criterios de intervención.

IV. Propuesta de Intervención: Tratamientos propuestos, materiales y productos a emplear y puesta a punto de métodos y técnicas de tratamiento.

V. Presupuesto y precios descompuestos

VI. Conclusiones redacción del documento de Proyecto de intervención

La fase de investigación-estudios preliminares contempla el levantamiento y restitución fotogramétricas a escala 1:20 del retablo mayor. Se dispondrá así de una cartografía exacta del retablo a partir de la cual se podrán representar de forma pormenorizada todos aquellos aspectos técnicos, científicos y conservativos derivados del proceso de estudio-investigación y de la intervención que sean necesarios (alteraciones, tratamientos, toma de muestras, etc).

Las investigaciones historiográficas, que se incluyen en esta fase, tienen un doble objetivo. Por un lado la profundización en el conocimiento de la historia material del retablo, su construcción, modificaciones estructurales, alteraciones y restauraciones, etc. Por otro lado, el análisis del retablo tanto desde la perspectiva de la calidad de la obra como del proceso(s) histórico(s) de su creación y consecuencias, utilizando para ello instrumentos de juicio conceptuales: Idea, análisis estilístico, análisis estructural, análisis simbólico e historiografía comparada.

Básicamente, la investigación científico-analítica permitirá, a partir de la toma de muestras de áreas significativas, una completa identificación analítica de materiales originales y añadidos, de sus alteraciones y evaluación de los productos de tratamiento.

Por último, esta fase se completa con una exhaustiva documentación fotográfica del es- tado de conservación y de la técnica de ejecución de los bienes, aplicando técnicas normales y especiales (U.V) así como con un examen radiográfico y reflectográfico (I.R.).

Completada la fase de investigación se estará en condiciones de realizar el diagnóstico del estado de conservación, en el que se incluye: determinación de la técnica de ejecución, de los factores de alteración, de las patologías presentes en cada uno de los estratos constitutivos y su interrelación. Asimismo se elaborará una amplia cartografía temática de la estructura arquitectónica del retablo, del soporte (lignario/lapídeo) y de la decoración/policromía.

Asimismo se procederá a la realización de estudios de correspondencia de capas polícromas/decorativas de algunos elementos escultóricos significativos y de una completa puesta punto de la técnica de intervención y de los productos a aplicar. Esta puesta a punto comprende, entre otros aspectos:

- Metodología de limpieza de la superficie polícroma/decorativa: test de solubilidad, realización de catas y determinación de los diferentes niveles de limpieza.

- Técnica de fijación/consolidación de los soportes y de la policromía/decoración.

- Técnica de reintegración de los soportes y de la policromía/decoración.

También serán objeto de evaluación los sistemas de anclaje de la estructura del retablo al soporte murario.

Por último se realizará un diagnóstico de los soportes textiles que forman parte del conjunto (pendones...) y se estudiará y formulará una propuesta de diseño de soporte y/o sistemas de sujeción de los paños litúrgicos del frontal de altar.

Tras ello, y en base a los resultados de los estudios efectuados, se elaborará la correspondiente propuesta de metodología de intervención y se definirán los criterios de intervención que se elevarán a la Comisión Tripartita de Seguimiento del Convenio para su estudio y aprobación, si procediera.

El plazo para desarrollar las investigaciones, estudios y redacción de proyecto es de seis meses. Se desea comenzar la fase de tratamiento a finales del próximo mes de setiembre. 